\title{
Effect of wetting and drying cycles on the durability of bio-cemented soil of expressway slope
}

\author{
S. Gowthaman ${ }^{1}$ (D) K. Nakashima ${ }^{1}$ (D) S. Kawasaki ${ }^{1}$
}

Received: 30 December 2020 / Revised: 14 March 2021 / Accepted: 30 March 2021 / Published online: 15 April 2021

(c) The Author(s) 2021

\begin{abstract}
Cyclic wet-dry is one of the influential weathering agents which can rapidly alter the mechanical properties of soils, limiting their durability and consistent performance. This study investigates the effect of wet-dry cycles on the mechanical behaviour of bio-cemented soil. Microbial-induced carbonate precipitation-based bio-cementation is an innovative soil improvement method, which is gaining increasing attention as a potential alternative for stabilizing slope surface. As the treated surfaces are exposed to repeated rainfalls and draughts, durability analysis is essential; cyclic wet-dry tests were therefore performed as a credible indicator of durability. The soil obtained from the Hokkaido expressway slope was treated at laboratory to varying cementation levels $\left(\% \mathrm{CaCO}_{3}\right)$ and subjected to 50 subsequent wet-dry cycles. Physical and mechanical changes were monitored using mass loss, shear wave velocities and needle penetration tests during wet-dry cycles. The results showed that the wet-dry cycles deteriorated the physical and mechanical at two stages. The mass and S-wave velocity of specimens significantly dropped after first few cycles and then tended to reach equilibrium. The second stage of notable deterioration was observed between 30 and 50 wet-dry cycles. It is suggested that the erosion of weak and powdery deposition of $\mathrm{CaCO}_{3}$ causes the degradation at the early stage, whereas the degradation in the late stage was attributed to the microstructural deformations of intact carbonate bonds. It was also found that the increase in cementation level decreases the deterioration of bio-cemented soil under wet-dry cycles.
\end{abstract}

Keywords Cementation level $\cdot$ Durability $\cdot$ Microbial induced carbonate precipitation $\cdot$ Slope surface $\cdot$ Stabilization $\cdot$ Wetdry cycles

\section{Introduction}

Over the decades, number of cementation-based soil stabilization methods have been developed and which are being applied in geotechnical engineering projects at a global scale. MICP (microbial induced carbonate precipitation) is relatively a novel bio-cementation method, developed at the confluence of bio-geochemical processes to improve the geotechnical properties of soils. The method utilizes non-pathogenic ureolytic microorganisms to mineralize the calcium carbonate bio-cement within soil matrix. Firstly, the hydrolysis of urea is catalysed by enzyme urease of soil

Editorial responsibility: M.Abbaspour.

S. Gowthaman

gowtham1012@outlook.com

1 Faculty of Engineering, Hokkaido University, Kita 13, Nishi 8, Kita-Ku, Sapporo 060-8628, Japan bacteria, resulting the formation of carbonate and ammonium ions (Eq. 1). In the subsequent step, the crystallization of $\mathrm{CaCO}_{3}$ occurs in calcium-rich aqueous media (Eq. 2), and the precipitated carbonates coat the soil grains, bind the particles effectively at particle contacts, eventually resulting the increase in strength of the soil (DeJong et al. 2010; Achal and Kawasaki 2016; Omoregie et al. 2020). Many investigations demonstrated that the MICP can be effectively implemented to various geotechnical applications including ground improvement (van Paassen et al. 2010; Kalantary and Kahani 2019; Badiee et al. 2019), liquefaction resistance in loose sands (Montoya et al. 2013; Moosazadeh et al. 2019), erosion control (Maleki et al. 2016; Wang et al. 2018; Jiang et al. 2019), coastal protection (Nayanthara et al. 2019; Imran et al. 2019) and stabilizing dust and loess (Meyer et al. 2011; Sun et al. 2020).

$$
\mathrm{CO}\left(\mathrm{NH}_{2}\right)_{2}+2 \mathrm{H}_{2} \mathrm{O} \stackrel{\text { microbial urease }}{\rightarrow} \mathrm{CO}_{3}^{2-}+2 \mathrm{NH}_{4}^{+}
$$


$\mathrm{Ca}^{2+}+\mathrm{CO}_{3}^{2-} \rightarrow \mathrm{CaCO}_{3}$ (deposition)

Among the wide range of potentials, application of MICP for the preservation of slope surface is gaining a great deal of interest among geotechnical engineers. One major reason is that the MICP offers numerous ecological benefits over conventional measures. For an instance, the Portland cement is the mostly used binder for slope protection (Daraei et al. 2018; Tang et al. 2018); however, its manufacturing contributes to the significant emission $\mathrm{CO}_{2}$ and $\mathrm{SO}_{2}$ (Alshalif et al. 2020). Besides, the synthetic grouts used for surface stabilization (such as polyacrylamide and phosphor-gypsum) are reported to be highly toxic (Jiang et al. 2019). In fact, MICP is a naturally occurring biogeochemical process in the earth's crust. The required bacteria are also found to be abundantly existing in soil environments. Therefore, MICP can be an eco-friendly alternative and can be applied to the slope surface with minimal soil-environmental damage.

The slopes are typically exposed to several climatic changes such as rainfall, snowfall, snowmelt and evapotranspiration. Surface erosion is a common slope degradation process; therefore, most of the existing studies focused on the responses under simulated rainfalls and wave effects. It was repeatedly shown that the MICP can significantly improve the erosion and scouring resistance of foreshore slopes when subjected to tidal wave effects (Salifu et al. 2016; Bao et al. 2017; Liu et al. 2020). In due course, few researchers assessed the impact of short-term rainfall on the surface erosion of sandy slopes (Jiang et al. 2019; Chung et al. 2020). The outcomes indicated that the calcium carbonate bonds formed between soil particles could markedly enhance the stability of surface aggregates against erosion. Recently, to apply the MICP in cold regions, Gowthaman et al. (2020) studied the durability characteristics of treated slope surface, showing that the durability under freeze-thaw actions is attributed to the effective cementation at particle contacts.

Cyclic wet-dry (WD) is another core slope weathering agent, and that has been a serious concern in geotechnical and geological engineering. Due to the direct contact with the atmosphere, the surface undergoes periodical WD cycles during (i) diurnal changes in rainy-sunny weathers (Tang et al. 2011) and (ii) subsequent processes of rainfallevapotranspiration (Tang et al. 2016). Numerous studies demonstrated that the WD cycles cause substantial irreversible deformations in the fabric of geomaterials. For instance, presence of swelling minerals was found to cause temporal changes in soft soils during WD, resulting in desiccation cracking, shrinkage and volumetric changes (Tang et al. 2011; Zhang et al. 2013). Repeated WD process significantly alters microstructure of soil aggregates, leading to deterioration in shear strength and compressibility (Tang et al. 2016). In the case of sedimentary materials, fracture energy reduction and chemical corrosive actions are the most reported deterioration mechanisms. Several research works evidenced that WD process significantly deteriorates the mechanical properties of calcarenite rocks and sandstone materials (Ciantia et al. 2014, 2015; Khanlari and Abdilor 2015). Since the responses of MICP-treated soils (cemented by $\mathrm{CaCO}_{3}$ ) are often comparable with natural carbonate/ sandstone sediments (Daryono et al. 2020), treated surface may more likely undergo similar deterioration during prolonged exposure to repeated WD process. A performance assessment with respect to durability is therefore necessary and recommended prior to the field applications. It is worth noting that the available information on weathering effects of MICP treatment under repeated WD actions are very limited.

The flowchart (Fig. 1) illustrates the sequence of entire research works carried out to introduce the MICP technique as a new alternative for the preservation of expressway slope surface in Hokkaido, Japan. As indicated in Fig. 1, the objective of this article is to investigate the effects of repeated WD actions on the physical and mechanical deterioration of MICP treated soil at a pilot-scale. The soil obtained from the Hokkaido expressway slope was prepared in cylindrical

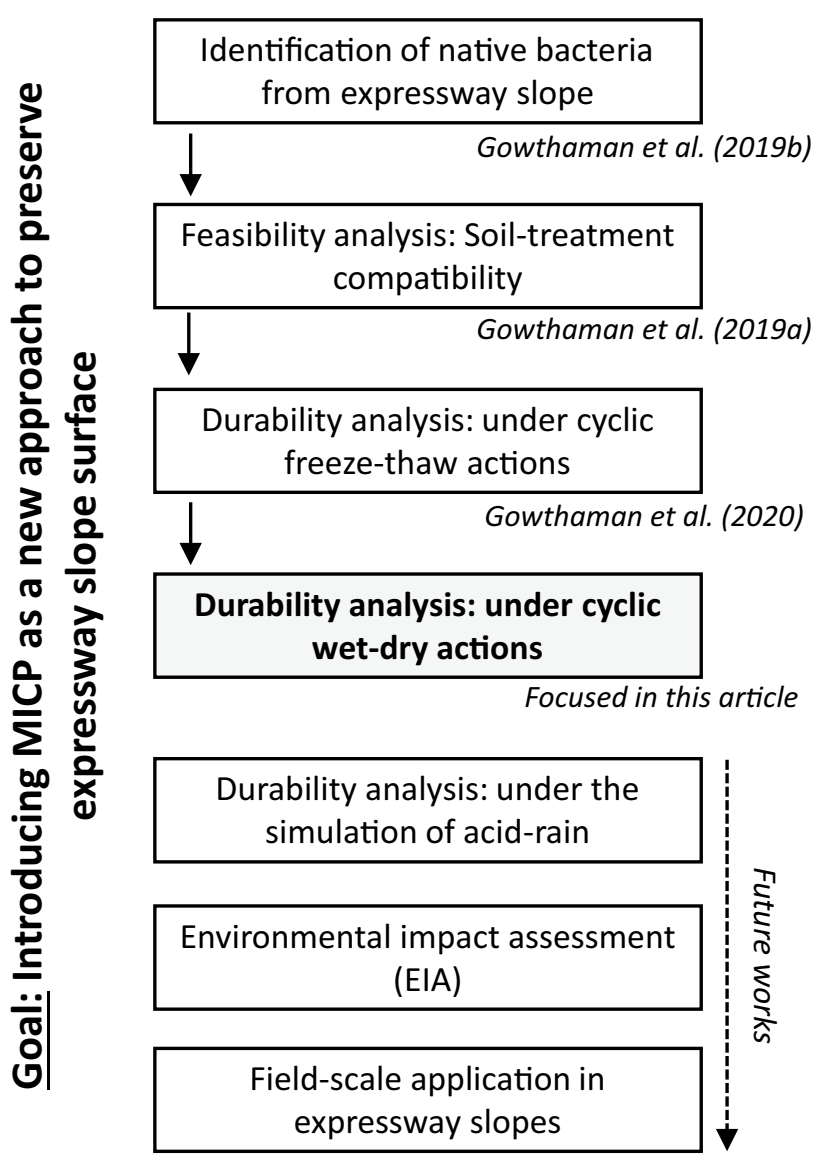

Fig. 1 Flowchart: the sequence of entire research works 
moulds and subjected to MICP treatment to varying cementation levels $\left(\% \mathrm{CaCO}_{3}\right)$, followed by the cyclic WD tests (up to 50 number of cycles). During the WD tests, the changes in physical and mechanical characteristics were evaluated by mass loss, S-wave velocity, unconfined compressive strength (UCS) measurements and scanning electron microscopy (SEM) and the results are discussed in detail.

(It should be mentioned that all the experiments were carried out at the Division of Sustainable Resources Engineering, Hokkaido University, Japan between October 2017 and September 2020).

\section{Materials and methods}

\section{Representative slope}

The soil used in the study was obtained from the erosion prone expressway slope (Do-O expressway line, Onuma) of Hokkaido, Japan. For the experimental purpose, disturbed soil samples were obtained at the site (the latitude and longitude are $42.388532 \mathrm{~N}$ and $140.284762 \mathrm{E}$, respectively). Fig. S1 (refer supplementary file) presents the particle size distribution curve of the soil. Based on the Unified Soil Classification System (USCS), the soil is classified as SP, poorly graded sand, consisting particle diameter at $50 \%$ finer by mass $\left(\mathrm{D}_{50}\right)$ of $0.23 \mathrm{~mm}$, coefficient of uniformity $\left(\mathrm{C}_{\mathrm{u}}\right)$ of 2.5 and coefficient of curvature $\left(\mathrm{C}_{\mathrm{c}}\right)$ of 0.8 . The basic characteristics and the chemical composition obtained from energydispersive X-ray fluorescence (XRF) analysis (JSX-3100R II JOEL, Japan) are provided in Table 1.

\section{MICP treatment procedure}

The soil samples were prepared into the cylindrical syringe moulds (30 $\mathrm{mm}$ in diameter; $50 \mathrm{~mm}$ in height) to a density of $1.6 \pm 0.1 \mathrm{~g} / \mathrm{cm}^{3}$. (The corresponding relative density was around $60 \%$ ). The experimental fabrication is shown in Fig. S2(a) (refer supplementary file). A two-phase treatment by surface percolation method was used similar to that suggested in many previous works (Cheng et al. 2013; Omoregie et al. 2019). In the first phase, the injection of bacteria culture was performed. The urease positive bacteria (Lysinibacillus xylanilyticus) which were isolated previously from the same target slope was cultivated at aerobic conditions (in shaking incubator at $25^{\circ} \mathrm{C}$ and $160 \mathrm{rpm}$ ) for $48 \mathrm{~h}$ in ammonium-yeast extract media (ATCC 1376) consisting
$20 \mathrm{~g} / \mathrm{L}$ of yeast extract, $15.75 \mathrm{~g} / \mathrm{L}$ of tris buffer and $10 \mathrm{~g} / \mathrm{L}$ of ammonium sulphate. Isolation and identification processes of the bacteria can be found in our previous work (Gowthaman et al. 2019a). The optical density value $\left(\mathrm{OD}_{600}\right)$ and urease activity of the bacteria culture during the injection were around 4.0 and $3 \mathrm{U} / \mathrm{mL}$, respectively (where, $1 \mathrm{U}$ defines the hydrolysis of 1 micromole urea per minute at $\mathrm{pH} 7.0$ at $25^{\circ} \mathrm{C}$ ).

In the second phase of the treatment, multiple cementation injections were performed until the required cementation level (\% $\mathrm{CaCO}_{3}$ by mass) was achieved. All the solutions were introduced to the specimen at the constant flow rate of $4 \mathrm{~mL} / \mathrm{min}$ using a peristaltic pump. The chemical recipe of cementation media consists of $111 \mathrm{~g} / \mathrm{L}$ of calcium chloride, $60 \mathrm{~g} / \mathrm{L}$ of urea and $6 \mathrm{~g} / \mathrm{L}$ of nutrient broth. As previously mentioned, the different levels of cementation were achieved by performing different number of the injections of cementation media. In this study, three cementation levels were considered: $\mathrm{C}-1, \mathrm{C}-2$ and $\mathrm{C}-3$. The average cementation level of $\mathrm{C}-1$ is between 12 and $13 \% \mathrm{CaCO}_{3}$. $\mathrm{C}-2$ is defined as an average cementation between 15 and $17 \%$, and the average cementation of $\mathrm{C}-3$ is $22-23 \% \mathrm{CaCO}_{3}$. To achieve the $\mathrm{C}-1, \mathrm{C}-2$ and $\mathrm{C}-3$ levels, total number of 7,10 and 14 injections of cementation media were, respectively, performed, and the injection was on every $24 \mathrm{~h}$ basis. The methodology used to determine the precipitated quantity of $\mathrm{CaCO}_{3}$ in treated specimens is elaborated in the following section.

It should be noted that as the enzymatic activity of the bacteria drops after 7 injections (which was confirmed by the drop in $\mathrm{pH}$ and increase in $\mathrm{Ca}^{2+}$ concentration at effluent), the bacteria injection was performed once again on 7 th day. The cementation levels considered in this study fall under the heavy cementation category (Feng and Montoya 2016). After the treatment, the moulds were cut, and the samples were carefully taken out. Finally, all samples were prudently trimmed to achieve smooth surfaces (attaining the final specimen size of $3 \times 3 \mathrm{~cm}$ : diameter $\times$ height). The appearance of the specimens treated to different cementation levels are shown in Fig. S2(b) (refer supplementary file).

\section{Determination of $\mathrm{CaCO}_{3}$ content}

The carbonate contents of the MICP specimens were determined by using a simplified device fabricated for the measurements of $\mathrm{CO}_{2}$ gas pressure during reactions (Fukue et al. 1999). After obtaining the oven dried
Table 1 Chemical composition and characteristics of soil used in this research

\begin{tabular}{llllllllllllll}
\hline Soil characteristics & \multicolumn{10}{l}{ Results of X-ray fluorescence (XRF) analysis (\%) } \\
\hline Moisture (\%) & $\mathrm{pH}$ & $\mathrm{MgO}$ & $\mathrm{Al}_{2} \mathrm{O}_{3}$ & $\mathrm{SiO}_{2}$ & $\mathrm{P}_{2} \mathrm{O}_{5}$ & $\mathrm{SO}_{3}$ & $\mathrm{~K}_{2} \mathrm{O}$ & $\mathrm{CaO}$ & $\mathrm{TiO}_{2}$ & $\mathrm{~V}_{2} \mathrm{O}_{5}$ & $\mathrm{MnO}$ & $\mathrm{Fe}_{2} \mathrm{O}_{3}$ \\
$10.5 \pm 0.7$ & 6.99 & 1.99 & 25.6 & 57.5 & 0.30 & 0.67 & 1.05 & 3.68 & 0.58 & 0.03 & 0.14 & 8.10 \\
\hline
\end{tabular}


mass $\left(105^{\circ} \mathrm{C}, 48 \mathrm{~h}\right)$, the samples were allowed to react with $3 \mathrm{~mol} / \mathrm{L}$ concentrated $\mathrm{HCl}$ in the closed system (of device) under constant temperature and volume conditions. Meanwhile, the internal pressure was monitored from the digital manometer connected with the system; the reading was recorded when the manometer read constant pressure. Using the calibration curve developed between quantity of calcium carbonate and pressure of $\mathrm{CO}_{2}$ gas released during reaction, the precipitated mass of $\mathrm{CaCO}_{3}$ was determined; hence, the cementation content (\%) was determined using Eq. 3. were subjected to a total number of 50 cycles. By the end of each WD cycle, the dry mass of the specimen (when the mass becomes constant during drying process) was recorded to evaluate the loss in mass.

As mentioned earlier, the specimens were treated to three levels of cementation $(\mathrm{C}-1, \mathrm{C}-2$ and $\mathrm{C}-3)$ to evaluate the influence of cementation level on durability of MICP treated soil. The details of the specimens subjected to WD analysis are summarized in Table 2 . The mechanical deterioration was continually evaluated by monitoring the shear wave velocity of the specimens and comparing

$\mathrm{CaCO}_{3}$ content $(\%)=\frac{\text { Weight of } \mathrm{CaCO}_{3} \text { (in the specimen) }}{\text { Weight of the oven dried specimen }- \text { Weight of } \mathrm{CaCO}_{3}}$

\section{Cyclic wet-dry (WD) tests and test cases}

The WD cycles were performed in accordance with the method suggested in ASTM (2003). In each wet-dry cycle, specimens were fully immersed into distilled water at room temperature $\left(25 \pm 1{ }^{\circ} \mathrm{C}\right)$ for $6 \mathrm{~h}$, followed by a minimum of $42 \mathrm{~h}$ of oven drying at $70 \pm 1{ }^{\circ} \mathrm{C}$. Specimens the UCS of control specimens (i.e. not subjected to wetdry tests) and tested specimens (i.e. after wet-dry cycles). In order to study the initial characteristics, a set of specimens was simultaneously treated to considered levels, and their as-treated characteristics were evaluated (shown in Table 3). In each case of analysis, experiments were performed in triplicate.
Table 2 Details of the specimens subjected to cyclic WD analysis

\begin{tabular}{llllll}
\hline Test category & $\begin{array}{l}\text { Specimen } \\
\text { designation }\end{array}$ & $\begin{array}{l}\text { Number of cemen- } \\
\text { tation injections }\end{array}$ & Initial $V_{\mathrm{s}}(\mathrm{m} / \mathrm{s})$ & $\begin{array}{l}\text { Cementation } \\
\text { category }\end{array}$ & $\mathrm{CaCO}_{3}$ (average) \\
\hline Wet-dry analysis & $\mathrm{C}-1-1$ & 7 & 1.15 & $\mathrm{C}-1$ & $12-13 \%$ \\
& $\mathrm{C}-1-2$ & 7 & 1.18 & & \\
& $\mathrm{C}-1-3$ & 7 & 1.13 & & \\
& $\mathrm{C}-2-1$ & 10 & 1.35 & $\mathrm{C}-2$ & $15-17 \%$ \\
$\mathrm{C}-2-2$ & 10 & 1.34 & & \\
$\mathrm{C}-2-3$ & 10 & 1.36 & & \\
$\mathrm{C}-3-1$ & 14 & 1.61 & $\mathrm{C}-3$ & \\
$\mathrm{C}-3-2$ & 14 & 1.87 & & \\
$\mathrm{C}-3-3$ & 14 & 1.59 & & \\
\hline
\end{tabular}

Table 3 Detail of the control specimens

\begin{tabular}{|c|c|c|c|c|c|c|c|c|}
\hline \multirow[t]{2}{*}{ Test category } & \multirow{2}{*}{$\begin{array}{l}\text { Specimen } \\
\text { designation }\end{array}$} & \multirow{2}{*}{$\begin{array}{l}\text { Cementation } \\
\text { category }\end{array}$} & \multirow{2}{*}{$\begin{array}{l}\text { Number of cementa- } \\
\text { tion injections }\end{array}$} & \multicolumn{3}{|c|}{ Vertical distribution of $\% \mathrm{CaCO}_{3}$} & \multirow{2}{*}{$\begin{array}{l}\text { Average } \\
\mathrm{CaCO}_{3}(\%)\end{array}$} & \multirow[t]{2}{*}{$\mathrm{UCS}(\mathrm{MPa})$} \\
\hline & & & & Top & Middle & Bottom & & \\
\hline \multirow[t]{9}{*}{ Control specimens } & $\mathrm{CO}-1-1$ & \multirow[t]{3}{*}{$\mathrm{C}-1$} & 7 & 14.11 & 12.80 & 10.72 & 12.54 & 2.41 \\
\hline & $\mathrm{CO}-1-2$ & & 7 & 14.74 & 13.18 & 9.87 & 12.60 & 2.01 \\
\hline & $\mathrm{CO}-1-3$ & & 7 & 13.21 & 12.42 & 11.22 & 12.28 & 2.41 \\
\hline & $\mathrm{CO}-2-1$ & \multirow[t]{3}{*}{$\mathrm{C}-2$} & 10 & 19.82 & 17.88 & 16.21 & 16.14 & 3.97 \\
\hline & $\mathrm{CO}-2-2$ & & 10 & 18.22 & 16.95 & 15.72 & 15.01 & 4.40 \\
\hline & $\mathrm{CO}-2-3$ & & 10 & 20.11 & 17.43 & 14.9 & 16.25 & 3.97 \\
\hline & $\mathrm{CO}-3-1$ & \multirow[t]{3}{*}{$\mathrm{C}-3$} & 14 & 24.73 & 22.76 & 19.65 & 22.38 & 12.89 \\
\hline & $\mathrm{CO}-3-2$ & & 14 & 25.21 & 22.00 & 20.49 & 22.57 & 12.89 \\
\hline & $\mathrm{CO}-3-3$ & & 14 & 26.22 & 21.86 & 19.31 & 22.46 & 9.73 \\
\hline
\end{tabular}




\section{Shear wave velocity measurement}

Shear wave velocities $\left(V_{\mathrm{s}}\right)$ of the specimens were determined after every WD cycle using high voltage pulse receiver (SonicViewer-SX: 5251, Japan). During measurement, MICP specimens were carefully positioned between transducers (transmitter and receiver), and the signals from the benders were captured using the two-channel digital oscilloscope at frequency bandwidth of $150 \mathrm{MHz}$. The elapsed time (digital oscilloscope, determined from the output waveforms) and the wave travel distance (sample height, measured by vernier caliper) were used to compute the shear wave velocity of the specimens, as shown in Eq. 4.

$V_{\mathrm{s}}=\frac{L}{t-\delta t}$

where $L$ is the distance between the transmitter and receiver (i.e. specimen height), and $t$ is the effective travel time of the signal from the transmitter to the receiver. $\delta t$ is the delay of the wave when there is no specimen placed, measured by assembling only transmitter and receiver.

\section{UCS measurement}

The UCS of the samples were estimated by needle penetration test (SH-70, Maruto Testing Machine Company, Tokyo, Japan) in accordance with JGS (2012). The tests were performed to the specimens after 12, 30 and $50 \mathrm{WD}$ cycles. Following the drying process, the needle of the device was gradually penetrated into the cylindrical surface of the specimen. Based on the obtained test results (penetration resistance and penetration depth), the UCS of the specimens were accurately estimated from the regression relationship developed (Eq. 5). It should be noted that needle penetration tests are widely being used by many other researchers as well for the evaluation of MICP treated specimens (Fukue et al. 2011; Danjo and Kawasaki 2016; Amarakoon and Kawasaki 2018; Gowthaman et al. 2019b).

$\log (y)=0.978 \log (x)+2.621$

where $y$ is the UCS; $x$ is the "penetration gradient $(\mathrm{N} / \mathrm{mm})$ " which can be determined using penetration resistance and penetration depth.

\section{SEM and XRD analysis}

To study the microstructural changes in the specimens, SEM analysis was performed using Miniscope TM 3000 (Hitachi, Tokyo, Japan) before and after the WD test. The representative samples were carefully taken from the samples and observed through SEM after the oven dry at $60{ }^{\circ} \mathrm{C}$. To better understand the chemical changes in the specimens during WD actions, XRD (X-Ray Diffraction) tests (MiniFlex ${ }^{\mathrm{TM}}$, Rigaku Co. Ltd., Tokyo, Japan) were performed before and after 12, $50 \mathrm{WD}$ cycles. The powdered samples were tested at a scan rate of $6.5^{\circ} / \mathrm{min}$ and at angles from $5^{\circ}$ to $70^{\circ}(2 \theta)$. The results obtained from the analysis are discussed comprehensively in the subsequent sections.

\section{Results and discussion}

\section{Distribution of calcium carbonate}

Level of cementation was found to be one of the most important factors determining the mechanical characteristics of MICP-treated soils (Feng and Montoya 2016; Gowthaman et al. 2020). As presented in Table 2, the specimens were treated herein to three levels of cementation, referred to as $\mathrm{C}-1, \mathrm{C}-2$ and $\mathrm{C}-3$ (corresponding to 7, 10 and 14 numbers of cementation injections, respectively). From the $\mathrm{CaCO}_{3}$ measurements shown in Table 3, it can be seen that the average precipitation content of $\mathrm{CaCO}_{3}$ gradually increases with the increasing treatment numbers, which is consistent with the tendency reported by Cui et al. (2017) for the sands treated by MICP. In addition, the shear wave velocity values of $\mathrm{C}-1, \mathrm{C}-2$ and $\mathrm{C}-3$ specimens are in a range between 1.1 and $1.2 \mathrm{~km} / \mathrm{s}, 1.3$ and $1.4 \mathrm{~km} / \mathrm{s}$ and 1.6 and $1.9 \mathrm{~km} / \mathrm{s}$ (Table 2), respectively, indicating that the velocity measurements have a close relationship with the precipitation content of $\mathrm{CaCO}_{3}$. As the mechanical strength due to MICP is achieved by the cementation at particle-particle contacts, the shear wave velocity measurement can be a credible measure to non-destructively assess the mechanical behaviour of treated specimens.

It is undoubtedly essential to evaluate the uniformity of $\mathrm{CaCO}_{3}$ precipitation with the depth, because the MICP is attained by injecting solutions from the surface of the specimens. For that, treated control specimens (Table 3) were prudently sectioned into three equal segments along the height (around $1 \mathrm{~cm}$ each), and measured calcium carbonate contents are plotted in Fig. 2 against depth. Slightly a heterogeneity in vertical distribution of $\mathrm{CaCO}_{3}$ is witnessed from the results of all the treatment levels. Cheng et al. (2014) also observed a similar distribution pattern when treating fine sand material. In fact, there are several factors determining the spatial distribution of $\mathrm{CaCO}_{3}$ along the depth including distribution of bacteria cells, chemical conversion and particle size distribution (Whiffin et al. 2007; Martinez et al. 2013). As the soil studied herein is a fine-grained soil, more bacteria cells were possibly filtered at around the injection top compared to bottom zone, which led to the gradient in the distribution (Fig. 2). It should be noted that in this study, the average $\mathrm{CaCO}_{3}$ value (\%) was used to represent 


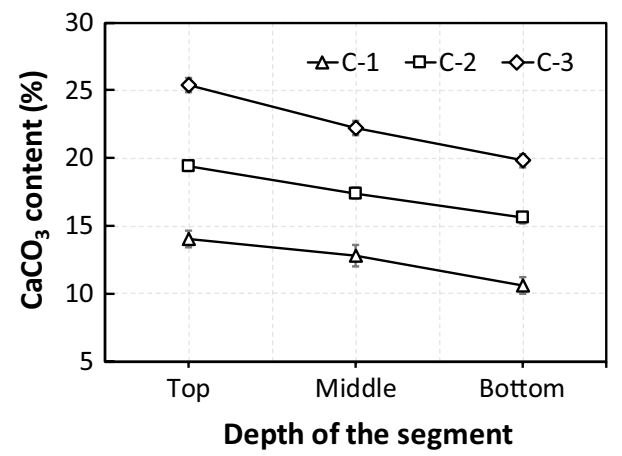

Fig. 2 Distribution of $\mathrm{CaCO}_{3}$ along the depth of the treated specimens

each cementation level (i.e. C-1: $12-13 \%, \mathrm{C}-2: 15-17 \%$ and C-3: 22-23\%).

\section{Cyclic WD analysis}

\section{Visual observation and mass loss}

Figure 3 presents the physical appearance of specimens treated to varying cementation levels before and after subjecting repeated WD cycles. As observed, the surfaces of the specimens were relatively smooth before subjected to WD test. By the end of 50 WD cycles, $\mathrm{C}-1$ specimens showed severely damaged surface with large open pores, indicating less durability under repeated WD actions. C-2 specimens exhibited a moderate level of surface damage, whereas the specimens cemented to C-3 level showed only a minor damage on the surface, suggesting higher resistance to the
WD-induced damages compared to that of C-1 and C-3. It should be noted that in all the cemented specimens, the damages could be prominently seen on the surface after around 30 WD cycles.

Figure 4a presents the cumulative mass loss of the specimens with increasing number of WD cycles. The results show that the specimens underwent an average mass loss in a range between 2 and $5 \%$ by the end of 50 cycles, which is in a good agreement with the mass loss reported to phosphate cement specimens under similar WD actions (Li et al. 2019). In addition, the level of cementation appears to influence the rate of loss in mass. By the end of the $50 \mathrm{WD}$ cycles, the scaled-off mass of the $\mathrm{C}-1, \mathrm{C}-2$ and $\mathrm{C}-3$ specimens were $4.4 \%, 2.8 \%$ and $2.4 \%$, respectively, suggesting more or less of the cementation level would in turn increase or decrease the resistance to aggregate loss.

Moreover, all the tested specimens revealed an abrupt increase in mass loss (over around $1.3 \%$ by weight) by the end of first WD cycle (Fig. 4a). However, within another few more WD cycles, the scaling-off decreased gradually and tended to reach an equilibrium state. Up to around 30 number of WD cycles, relatively flat graphs were obtained in all the test cases, suggesting that the loss of mass were negligible within this equilibrium phase. A similar tendency in mass loss was also reported by Ciantia et al. (2015) to the calcarenite specimens when subjected to repeated WD cycles. When the MICP specimens were subjected to further WD cycles (above 30), mass loss became significant once again. At this later period, increased loss rate was evidenced in $\mathrm{C}-1$ specimens, whereas the loss rates experienced in $\mathrm{C}-3$ specimens were lower compared to $\mathrm{C}-1$ (around 1.8 times) under WD actions.
Fig. 3 Physical appearance of cemented specimens when subjected to repeated WD cycles
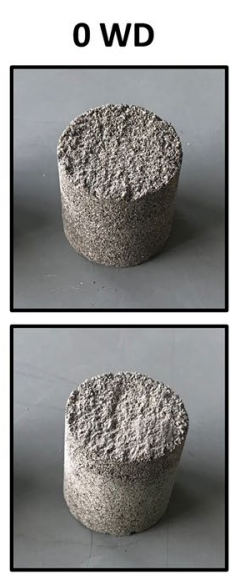

C-2

C-3

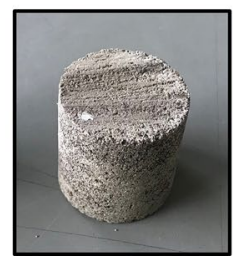

\section{WD}
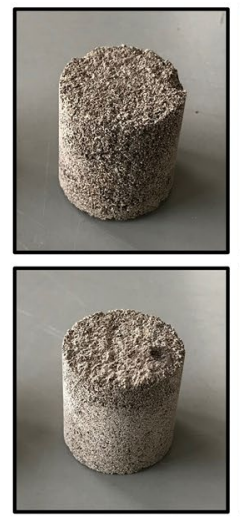

20 WD
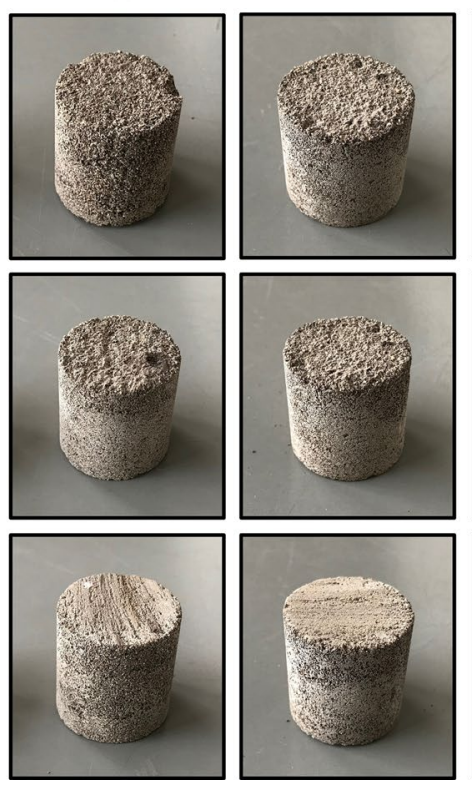

30 WD
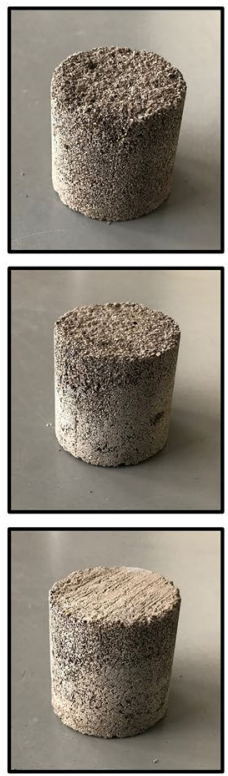

50 WD
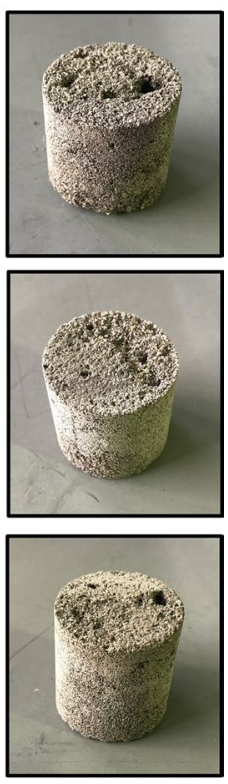

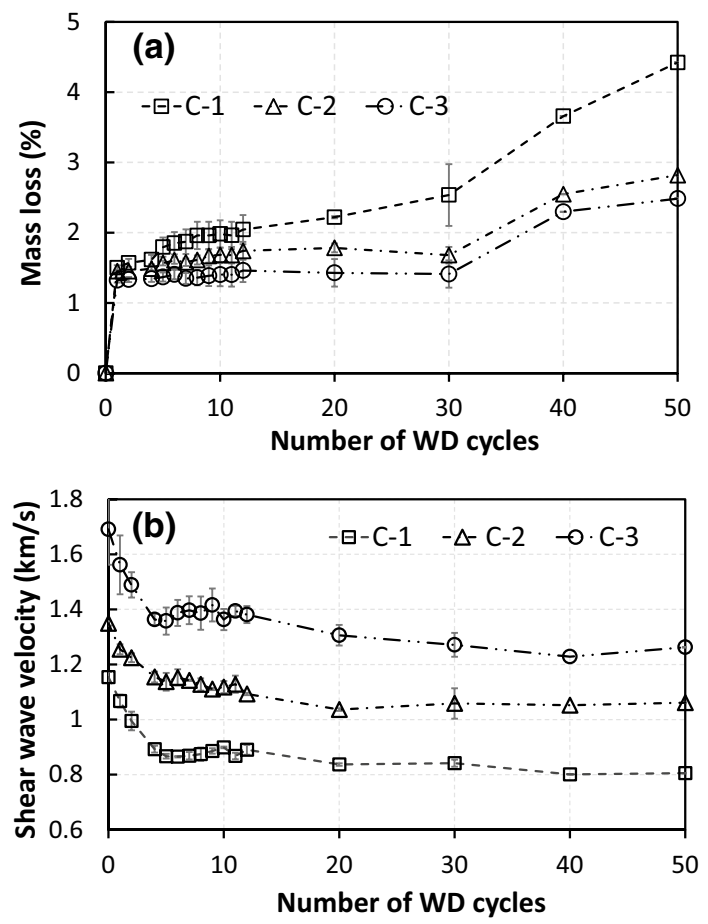

Fig. 4 Variation in a mass loss and b shear wave velocity of cemented specimens with repeated WD cycles

\section{Shear wave velocity}

For better understanding the changes in the mechanical behaviour of cemented specimens, shear wave velocities were measured periodically with the increase in number of WD cycles, and the results are provided in Fig. 4b. It is worth noting that the precipitated calcium carbonate at particle contact has the utmost effect in shear wave velocity of the specimens, because the shear waves can only be transmitted through solids (not through soil pores) (Al Qabany et al. 2011). Therefore, shear wave measurements were frequently used as a credible monitoring tool for MICP cemented specimens (Feng and Montoya 2016; Gowthaman et al. 2020), demonstrating that the more or less/ strong or weak connections of soil particles would result, respectively, high or low velocity values. From Fig. 4b, it can be seen that the variation in velocity measurements follows relatively a similar pattern in all the cementation cases with increasing WD cycles, i.e. a rapid drop was observed at the early stage (within around 5 WD cycles), followed by a smooth and gradual reduction. It is worth mentioning that the tendency observed in velocity measurements (Fig. 4b) shows a good agreement with pattern observed in scale-off mass (Fig. 4a). This explains that the rapid reduction in velocity at early stage (up to $25 \%$ ) could be attributed to the weakening of particle connections due to the erosion induced by WD process. Furthermore, the velocity reduction taken place within

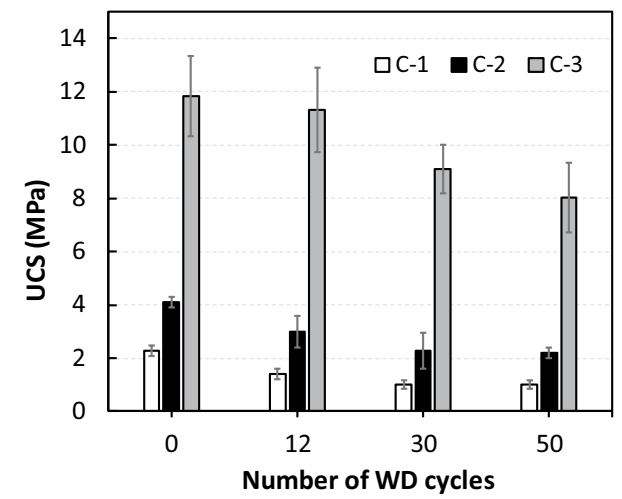

Fig. 5 UCS of the specimens against number of WD cycles

5-50 WD cycles was comparatively lower than that befell during early stage ( $0-5$ cycles), suggesting that the impairment during early stage of WD process was noteworthy.

\section{Unconfined compressive strength}

Figure 5 shows the variation in UCS of MICP treated specimens after the exposure of $0,12,30$ and $50 \mathrm{WD}$ cycles. Before subjected to the WD cycles, the average UCS of $\mathrm{C}-1, \mathrm{C}-2$ and $\mathrm{C}-3$ cemented specimens were $2.3,4.1$ and $11.8 \mathrm{MPa}$, respectively. After subjected to $12 \mathrm{WD}$ cycles, $\mathrm{C}-1$ and $\mathrm{C}-2$ specimens showed significant loss in UCS, which were, respectively, around $38 \%$ and $27 \%$ relative to those of control specimens. On the other hand, $\mathrm{C}-3$ specimens showed inconsequential destruction in strength (which was only $4.5 \%$ ), indicating higher durability against WD effects compared to $\mathrm{C}-1$ and $\mathrm{C}-2$. Nevertheless, the UCS continued to decrease gradually in all the cases with increasing cycles, and by the end of 50 cycles, the reduction in UCS were $55 \%, 46 \%$ and $32 \%$ for $\mathrm{C}-1, \mathrm{C}-2$ and $\mathrm{C}-3$ specimens, respectively. It is clearly perceived the strength deterioration conspicuously occurs throughout the WD process, but the overall deterioration rate is more likely to be determined by the level of cementation.

\section{XRD analysis}

Fig. S3 (refer supplementary file) shows the results of XRD analysis which was performed to verify the occurrence of phase transformation of carbonate deposits, precipitation of new minerals and dissolving of existing minerals. The results suggest that the morphology of the precipitated calcium carbonate before the WD tests was completely calcite. Basically, the calcium carbonate can precipitate in various forms of polymorph such as calcite (rhombohedral shape), vaterite (spherical shape), aragonite (typically clustered needles) and amorphous calcium carbonates (ACC, nanoparticles), which is determined by reaction kinetics and thermodynamic 
effects (Dhami et al. 2013; Tolba et al. 2016). The formation of least-stable phases (such as vaterite and ACC) at the initial stage of reaction might get transformed into stable phase (such as calcite) (Wang et al. 2019). However, the XRD results confirm that there are no observable changes in the morphology of minerals throughout the WD process. The observed peaks are identical with the increase in number of cycles, suggesting neither formation of new minerals nor phase changes were induced.

\section{Discussion}

\section{Deterioration mechanism of MICP treated soil}

In this study, the MICP was investigated as a cementation material to treat the soil. The treatment is attained through the surface percolation; most of the bacteria cells are therefore tended to aggregate at particle contacts, leading to a preferential formation of calcium carbonate at or near the contact points of soil particles (DeJong et al. 2010). However, as the crystallization process had already begun during the percolation phase (Whiffin et al. 2007), not all the precipitated carbonates contribute to the contact cementation; a considerable quantity of carbonates either crystallize randomly on the soil grains or set on the already formed carbonate bridges. Micrographs depicted in Fig. 6a, b clearly illustrate different forms of calcium carbonate deposits. As shown, the secondary formations of the calcium carbonate could embed as accumulated carbonate clusters (marked as B), individual clusters (marked as C) and powdery deposits (marked as D), and the microstructure reported herein is consistent with the micrographs of many previous works (Bao et al. 2017; Wu et al. 2019).

It is clearly perceived that the physical and mechanical behaviours are significantly influenced by the WD cycles. From the results of both mass loss and $V_{\mathrm{s}}$ measurements (Fig. 4a, b), it is evident that the performance deterioration of specimens occurs namely in two stages. In the early stage (within 5 WD cycles), a severe degradation was witnessed,

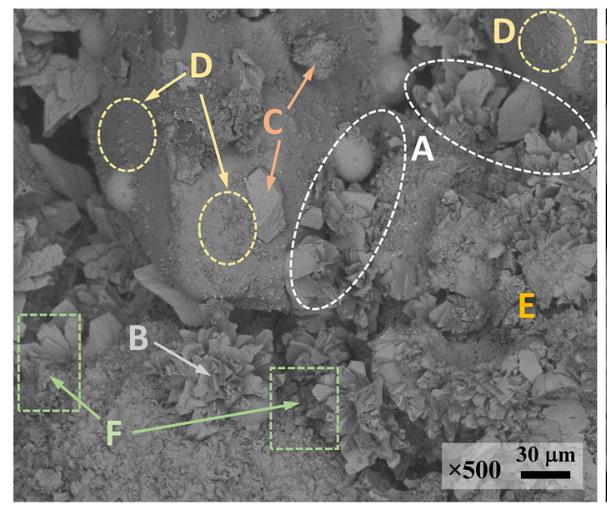

(a)

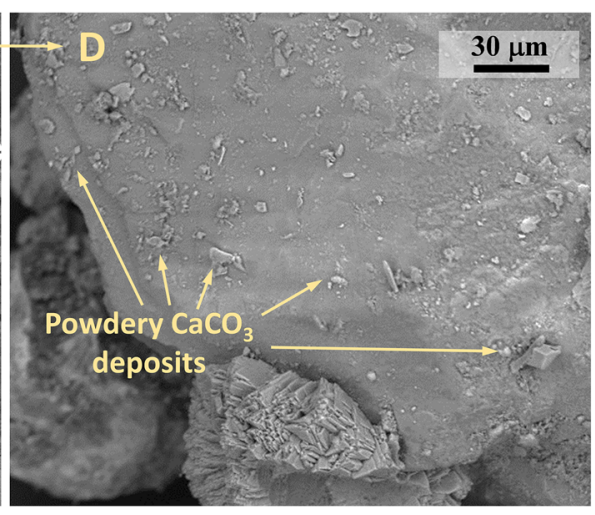

(b)

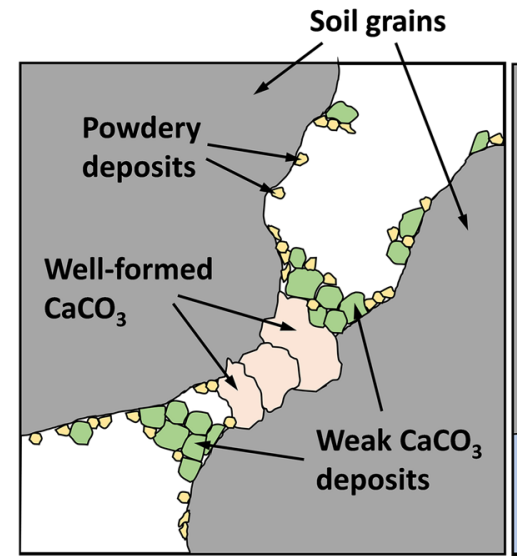

(c)

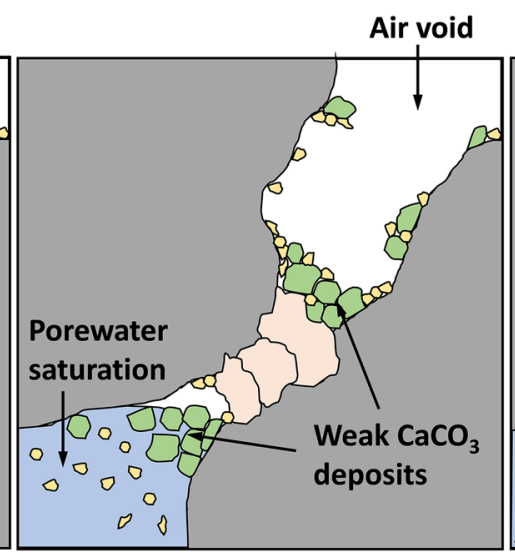

(d)

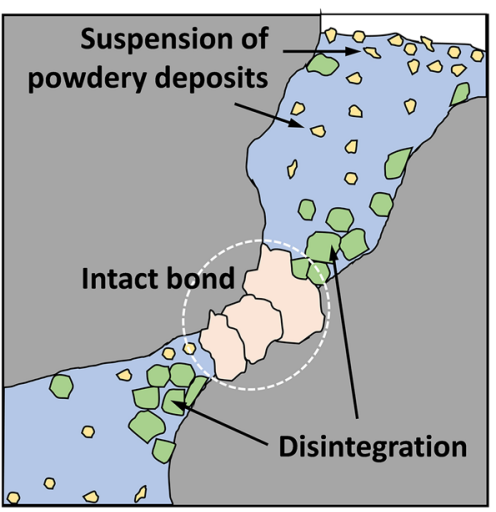

(e)
Fig. 6 a Microstructure of MICP soil (A: $\mathrm{CaCO}_{3}$ well deposited at particle contacts; $\mathrm{B}$ : $\mathrm{CaCO}_{3}$ assemblage; $\mathrm{C}$ : individual crystals; $\mathrm{D}$ : powdery $\mathrm{CaCO}_{3}$ deposits; $\mathrm{E}$ : accumulation of $\mathrm{CaCO}_{3}$ deposits; $\mathrm{F}$ : deposits supporting large carbonate clusters), b powdery $\mathrm{CaCO}_{3}$ deposits, c schematic illustration of MICP soil before subjected to wetting, $\mathbf{d}$ wetting process: penetration of water into pores, and $\mathbf{e}$ wetting process: saturated stage 
hereafter referred to as STD (short-term deterioration). In the subsequent stage, a gradual degradation was observed, which is hereafter referred to as LTD (long-term deterioration).

\section{Short-term deterioration (STD)}

The STD mechanism can be explained from the evolution of calcium carbonate precipitates during MICP treatment process. As demonstrated by Wang et al. (2019), during the injection of cementation solution, the calcium carbonates are initially induced as irregular precipitates (non-crystalline), and they continue to grow with the time and transform as regular calcium carbonate crystals (e.g. calcites) in the aqueous media. However, in many situations (e.g. deficiency of resources, presence of organic content in reaction system), the induced non-crystalline precipitates tend to stabilize on soil surfaces before transforming to crystalline structure. Figure $6 \mathrm{~b}$ shows the magnified micrograph, clearly depicting such powdery forms of $\mathrm{CaCO}_{3}$ attached ubiquitously on the grain surface. Similar powdery deposits of calcium carbonate were also observed previously during the formation of calcarenite rocks (Ciantia et al. 2015). It is therefore clear that the MICP treated soils consist of both strong and weak deposits of calcium carbonate.

Figure $6 c, d$, and e show the serial progression of water inundation during the initial wetting process. Figure $6 \mathrm{c}$ schematically illustrates the microstructure of MICP treated soil matrix, representing the existence of different types of carbonate bonds. When the samples are initially subjected to the wetting, water tends to penetrate through the porous system and inundate the material, resulting the powdery deposits and their accumulations to fall into suspension (Fig. 6d, e), followed by the erosion. This could attribute to the leap increase in mass loss observed after first WD cycle (Fig. 4a). It should be noted that at the early stage, the erosive mechanism is dominant, as the dissolution of calcium carbonate is relatively low under the standard wetting conditions (Ciantia and Hueckel 2013). By the end of first cycle, layer of powdery formations was evidenced at the bottom of the container wherein the samples were subjected for wetting, which further corroborated the mechanism suggested herein. Following the first cycle, the mass loss tended to become relatively stable (in another 3-4 cycles), suggesting that the powdery deposits have totally been eroded. Moreover, the rapid drop observed in $V_{\mathrm{s}}$ measurements within first 5 cycles (Fig. 4b) could be attributed to the disintegration of powdery and weak deposits. As demonstrated in Fig. 6c, there are also carbonate clusters which are feebly bonded, unlike primary intact bonds which are well-formed. Despite weakly attached, they had a substantial contribution in strengthening particle connections through supporting primary bonds. The repeated inundation during 5 WD cycles would disintegrate the deposits as illustrated in Fig. 6d, e, resulted in weakening of particle connections. This eventually caused the rapid loss in $V_{\mathrm{s}}$ and UCS of the specimens within the short-term.

Numerous WD degradation mechanisms were proposed for geomaterials such as fracture energy reduction, capillary tension decrease, chemical and corrosive deterioration, frictional reduction, etc.; however, they vary from material to material and depend on the exposure conditions (Zhao et al. 2017). Clay materials or the soils consisting certain fraction of clay are more susceptible to WD process, exhibiting rapid deterioration (Albrecht and Benson 2001; Tang et al. 2011). For instance, Tang et al. (2011) observed the formation of numerous large inter-aggregate pores in clayey soil after only 2 WD cycles due to the desiccation cracking and increase in bulk volume. The largest increase in hydraulic conductivity and shrinkage strains in clay occurred after the first WD cycle (Albrecht and Benson 2001). It is worth mentioning that the STD mechanism of MICP treated soils are more likely to be comparable with that of carbonatic rocks. Ciantia et al. (2015) found the occurrence of instantaneous debonding of depositional bonds (menisci shaped calcite ensembles) in carbonatic rocks when subjected to the saturation, and a single wetting process caused considerable loss in compressive strength.

\section{Long-term deterioration (LTD)}

When the specimens were subjected to further WD cycles, the MICP-treated specimens continuously underwent deterioration (refer to Fig. 4). However, this LTD was not as rapid as that observed in early stage (i.e. STD).

Figure 7a, b presents the SEM images captured, respectively, before and after the cyclic WD process. All the micrographs presented herein are captured at same magnification and scale (indicated at bottom right of each figure). From the comparison, a substantial change in the microstructure can be observed after subjected to prolonged WD actions. Before subjected to the WD test (control specimens), the presence of large carbonate clusters was evidenced in SEM (Fig. 7a). The appearance indicates that the calcite morphology found in control specimens was cauliflower-like crystallization, evolved by the accumulation of rod shape calcite clusters (Zhang et al. 2017). On the other hand, by the end of $50 \mathrm{WD}$ cycles, a substantial deformation was observed in carbonate deposits (Fig. 7b), and the cauliflower-like morphology could not be seen anywhere in the matrix. It should be noted that the results of XRD analysis (refer Fig. S3 in supplementary file) confirmed that the deformation is not related to the chemical changes or phase transformations; therefore, this deformation might be possibly due to the effects from the development of internal stresses during cyclic WD process as reported by Li et al. (2019). The difference in thermal expansion coefficient of calcite and soil material could result in the development of fatigue stresses during cyclic WD 
Fig. 7 The SEM images of MICP treated specimens a before subjected to WD cycles and $\mathbf{b}$ after the exposure of 50 WD cycles (a)
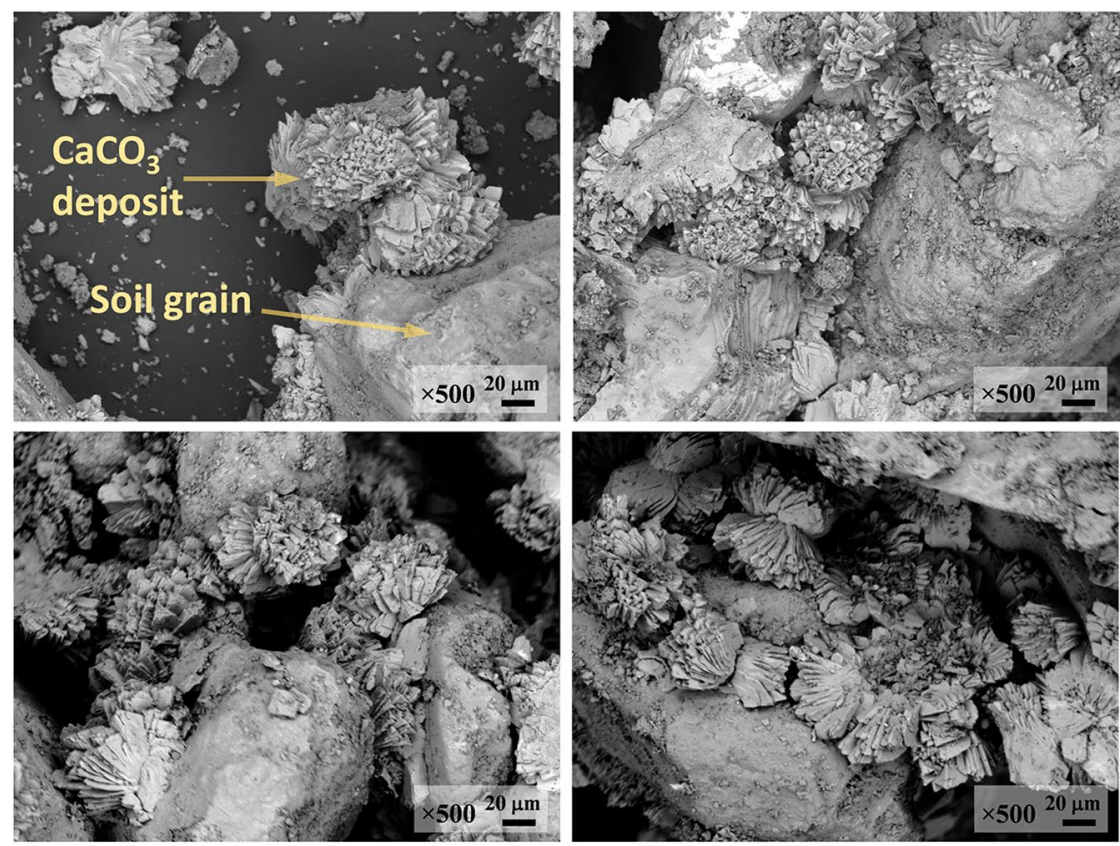

(b)
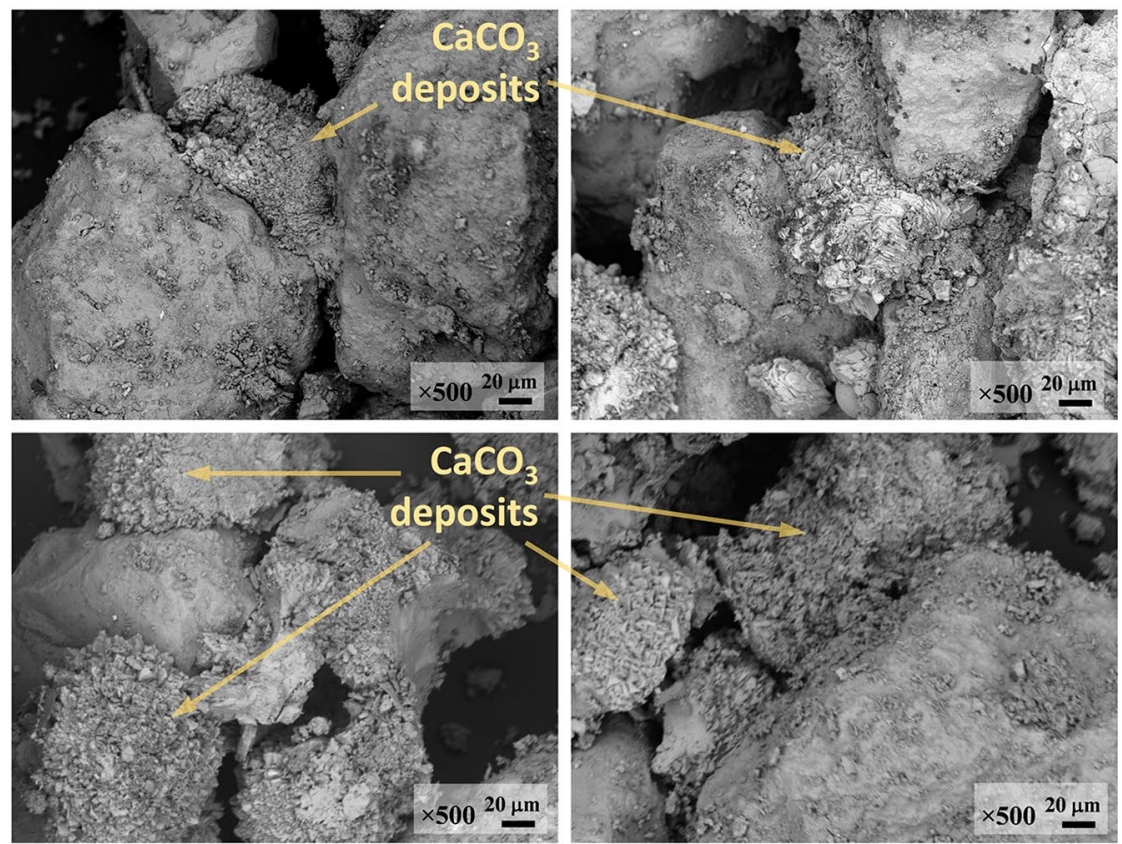

process (due to temperature change), led the calcite crystals to undergo deformation.

It should be noted that the destruction in MICP specimens due to the fatigue stresses was clearly observable at the later stage of WD process. For example, sharp increase in mass loss was once again prominently noticed after around 30 number of cycles (Fig. 4a). During this stage, soil particles tended to detach from the surface of the specimens, and rapid progression of macropores was experienced around surface (refer to Fig. 3). Fig. S4 (refer supplementary file) shows the microstructure of the deteriorated specimen surface (after 50 cycles). The observation reveals that the specimen surface underwent higher destruction compared to that observed around core of the specimens (Fig. 7b). As specified in Fig. S4, the calcite precipitated around the surface was observed to be impaired in addition to the deformation of calcite morphology. Microcracks were also observable at around the intact bonds. It is clear that the core zone of the sample is confined stiffly; therefore, the developed fatigue stresses caused more damages on the outer surface of the specimens, led to the weakening of soil aggregation and subsequent detachments. Similar surface degradations due 
to WD stresses were also observed by several researchers for cemented specimens (Zhang et al. 2012; Gao et al. 2014).

It was reported that when the calcites are flooded by water for a long time, a minor portion of carbonate would undergo chemical dissolution (Ciantia et al. 2014; Khanlari and Abdilor 2015). Ciantia et al. (2015) have confirmed that the LTD of carbonatic rocks is due to the dissolution of diagenetic calcite bonds. However, in this study, the effect of dissolution is assumed to be negligible under the standard conditions.

\section{Effect of cementation level on the durability of MICP treatment}

As explained earlier, three levels of cementation $(\mathrm{C}-1, \mathrm{C}-2$ and $\mathrm{C}-3$ ) were investigated in this study. The WD test results clearly reveal that all the specimens experienced physical and mechanical deterioration under the exposure of continuous WD cycles. However, the cementation level is found to have a marked impact on the durability of MICP treated soil. The comparison presented in Fig. 8 reveals the effect of cementation level on the durability of MICP treated soil (UCS and mass losses after $50 \mathrm{WD}$ cycles are compared). By the end of 50 WD cycles, the losses in UCS were 55\%, $46 \%$ and $32 \%$ for $12-13 \%(\mathrm{C}-1), 15-17 \%(\mathrm{C}-2)$ and $22-23 \%$ (C-3) cemented specimens, respectively, which demonstrates that the durability of specimens increases with the increase in cementation level. A similar impact of cementation level on the cumulative mass loss could also be seen from the comparison (Fig. 8). The increased durability could be attributed to the formation of strong intact bonds during longer treatments. The longer treatment (e.g. C-3) resulted in higher precipitation of $\mathrm{CaCO}_{3}$ at around particle-particle contact points, enhancing the resistance to the deterioration of calcite bridges and detachment of soil particles due to fatigue stresses developed during repeated WD cycles.

In a slope (as illustrated in Fig. S5 of supplementary file), surface zone/near-surface serves as the buffer-layer between

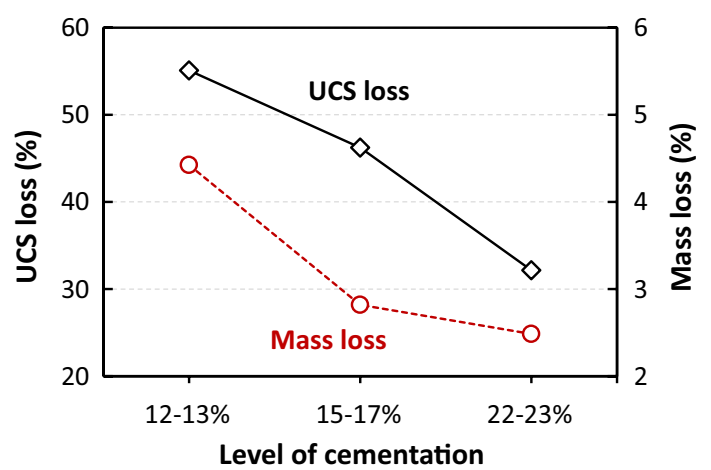

Fig. 8 Effect of cementation level on the durability of MICP treated specimens atmosphere and inner substrates, significantly determining the slope responses such as infiltration, aggregate stability and deterioration processes (Dai et al. 2018; Zhang et al. 2018). During the MICP treatment, surface substrates would be cemented together by precipitated calcium carbonate. It is very clear that the treated surface would have a crucial role on the stability of the expressway slope by functioning as a cover material. As demonstrated in this laboratory study, the MICP-treated surface would gradually weaken under the exposure to repeated wetting and drying processes, i.e. due to rainfall, evapotranspiration and draughts. It is worth mentioning that an effective application (slope cover) requires compatibility of its permanence and durability with service life requirements. Treating the soil to $12-13 \%$ of $\mathrm{CaCO}_{3}$ (i.e. $\mathrm{C}-1$ ) is shown to have less durability in terms of aggregate stability and strength, yet the longevity is found to be increased by around two times when treated to $22-23 \%$ of $\mathrm{CaCO}_{3}$ (i.e. C-3). Moreover, by deploying the MICP treatment to the slope surface, Jiang et al. (2019) found that high cementation resulted in less erosion, preserving slope surface against rainfall-induced damages. Gowthaman et al. (2020) demonstrated that the aggregate stability is attributed to the precipitation content of carbonate that resists the crystal-soil ruptures and detachments during the freeze-thaw. It is therefore clear that more precipitation of calcium carbonate corresponds to high durability of MICPtreated slope surface regardless of the environmental and/ or climatic factors.

\section{Conclusion}

MICP based bio-cementation has recently gained an increased attention as a promising alternative for the preservation of slope surface. In this study, the durability of MICP treatment upon cyclic wet-dry actions was evaluated at laboratory scale. The soil from Hokkaido expressway slope was treated by MICP and then subjected to continuous 50 number of WD cycles. During the WD cycles, changes in physical and mechanical responses were monitored using mass loss, S-wave velocities and UCS measurements. SEM was also performed to analyse the microstructural changes caused by WD actions. Based on the results, the following conclusions are drawn.

With the increase in number of WD cycles, the index properties of the specimens showed considerable deterioration in comparison with their initial values. Based on the observation, cyclic WD effects appeared to have adverse effects on the physical and mechanical characteristics of MICP-treated specimens. The study demonstrated that the deterioration is related to the degradation of calcium carbonates deposited in soil matrix, and that occurred in two stages: short-term and long-term. The short-term deterioration 
(STD) was significant, occurred rapidly within the first few WD cycles due to the suspension and erosion of weak carbonate deposits, resulting in significant loss of mass, shear wave velocity and UCS. The long-term deterioration (LTD) was not as significant as STD, occurred gradually, was prominently observable after around 30 number of WD cycles. SEM analysis demonstrated that intact carbonate deposits was deformed due to the fatigue stresses developed during repeated WD process. The developed stresses imposed increased degradation at surface of the specimens compared to that of core, which led to the detachment of surface particles and progression of macropores.

Moreover, it was found that the increase in cementation level would increase the durability of the MICP-treated specimens. When the soil was treated to high cementation level, the contact points were bonded strongly, which enhanced the resistance to the deterioration of calcite bridges due to WD fatigue stresses developed. The losses in mass and UCS were found to reduce by $41 \%$ and $55 \%$ when the cementation level in soil increased from $12-13$ to $22-23 \%$, indicated the enhancement in service life by around 2 times.

Supplementary Information The online version contains supplementary material available at https://doi.org/10.1007/s13762-021-03306-1.

Acknowledgement The authors would like to acknowledge the Hokkaido Regional Head Office, East Nippon Expressway Company Limited, Sapporo, Hokkaido, Japan, for the collaboration and supports provided throughout the research work.

Funding This research work did not receive any specific grant from funding agencies in the public or commercial sectors.

Data availability All the experimental data that support the findings of this study are available from the corresponding author upon reasonable request through email.

\section{Declarations}

Conflict of interest The authors declare that there are no conflicts of interest.

Ethical approval This article does not contain any studies with human participants or animals performed by any of the authors.

Open Access This article is licensed under a Creative Commons Attribution 4.0 International License, which permits use, sharing, adaptation, distribution and reproduction in any medium or format, as long as you give appropriate credit to the original author(s) and the source, provide a link to the Creative Commons licence, and indicate if changes were made. The images or other third party material in this article are included in the article's Creative Commons licence, unless indicated otherwise in a credit line to the material. If material is not included in the article's Creative Commons licence and your intended use is not permitted by statutory regulation or exceeds the permitted use, you will need to obtain permission directly from the copyright holder. To view a copy of this licence, visit http://creativecommons.org/licenses/by/4.0/.

\section{References}

Achal V, Kawasaki S (2016) Biogrout: a novel binding material for soil improvement and concrete repair. Front Microbiol. https://doi.org/ 10.3389/fmicb.2016.00314

Al Qabany A, Mortensen B, Martinez B, et al (2011) Microbial carbonate precipitation: Correlation of S-wave velocity with calcite precipitation. In: Geotechnical Special Publication. American Society of Civil Engineers, Reston, VA, pp 3993-4001

Albrecht BA, Benson CH (2001) Effect of desiccation on compacted natural clays. J Geotech Geoenvironmental Eng 127:67-75. https://doi.org/10.1061/(ASCE)1090-0241(2001)127:1(67)

Alshalif AF, Irwan JM, Othman N et al (2020) A systematic review on bio-sequestration of carbon dioxide in bio-concrete systems: a future direction. Eur J Environ Civ Eng. https://doi.org/10. 1080/19648189.2020.1713899

Amarakoon GGNN, Kawasaki S (2018) Factors affecting sand solidification using MICP with Pararhodobacter sp. Mater Trans 59:72-81. https://doi.org/10.2320/matertrans.M-M2017849

ASTM (2003) Standard test methods for wetting and drying compacted soil-cement mixtures (D559-03). American society for testing and materials, West Conshohocken, PA

Badiee H, Sabermahani M, Tabandeh F, Saeedi Javadi A (2019) Application of an indigenous bacterium in comparison with Sporosarcina pasteurii for improvement of fine granular soil. Int J Environ Sci Technol 16:8389-8400. https://doi.org/10. 1007/s13762-019-02292-9

Bao R, Li J, Li L et al (2017) Effect of microbial-induced calcite precipitation on surface erosion and scour of granular soils proof of concept. J Transp Res Board 2657:10-18. https://doi.org/10. 3141/2657-02

Cheng L, Cord-Ruwisch R, Shahin MA (2013) Cementation of sand soil by microbially induced calcite precipitation at various degrees of saturation. Can Geotech J 50:81-90. https://doi.org/ 10.1139/cgj-2012-0023

Cheng L, Shahin MA, Cord-Ruwisch R (2014) Bio-cementation of sandy soil using microbially induced carbonate precipitation for marine environments. Geotech 64:1010-1013. https://doi.org/ 10.1680/geot.14.T.025

Chung H, Kim SH, Nam K (2020) Application of microbially induced calcite precipitation to prevent soil loss by rainfall: effect of particle size and organic matter content. J Soils Sedim. https://doi.org/10.1007/s11368-020-02757-2

Ciantia MO, Hueckel T (2013) Weathering of submerged stressed calcarenites: chemo-mechanical coupling mechanisms. Geotech 63:768-785. https://doi.org/10.1680/geot.SIP13.P.024

Ciantia MO, Castellanza R, di Prisco C (2014) Experimental study on the water-induced weakening of calcarenites. Rock Mech Rock Eng 48:441-461. https://doi.org/10.1007/s00603-014-0603-z

Ciantia MO, Castellanza R, Crosta GB, Hueckel T (2015) Efects of mineral suspension and dissolution on strength and compressibility of soft carbonate rocks. Eng Geol 184:1-18. https://doi. org/10.1016/j.enggeo.2014.10.024

Cui MJ, Zheng JJ, Zhang RJ et al (2017) Influence of cementation level on the strength behaviour of bio-cemented sand. Acta Geotech 12:971-986. https://doi.org/10.1007/s11440-017-0574-9

Dai Q, Peng X, Wang P et al (2018) Surface erosion and underground leakage of yellow soil on slopes in karst regions of southwest China. L Degrad Dev. https://doi.org/10.1002/ldr.2960

Danjo T, Kawasaki S (2016) Microbially induced sand cementation method using pararhodobacter sp. strain SO1, inspired by beachrock formation mechanism. Mater Trans 57:428-437. https://doi.org/10.2320/matertrans.M-M2015842 
Daraei A, Herki BMA, Sherwani AFH, Zare S (2018) Slope stability in swelling soils using cement grout: a case study. Int J Geosynth Gr Eng 4:10. https://doi.org/10.1007/s40891-018-0127-9

Daryono LR, Nakashima K, Kawasaki S et al (2020) Sediment characteristics of beachrock: a baseline investigation based on microbial induced carbonate precipitation at krakal-sadranan beach, yogyakarta. Indones Appl Sci 10:520. https://doi.org/ 10.3390/app10020520

DeJong JT, Mortensen BM, Martinez BC, Nelson DC (2010) Biomediated soil improvement. Ecol Eng 36:197-210. https://doi. org/10.1016/j.ecoleng.2008.12.029

Dhami NK, Reddy MS, Mukherjee MS (2013) Biomineralization of calcium carbonates and their engineered applications: a review. Front Microbiol 4:1-13. https://doi.org/10.3389/fmicb.2013.00314

Feng K, Montoya BM (2016) Influence of confinement and cementation level on the behavior of microbial-induced calcite precipitated sands under monotonic drained loading. J Geotech Geoenvironmental Eng 142:04015057. https://doi.org/10.1061/ (ASCE)GT.1943-5606.0001379

Fukue M, Nakamura T, Kato Y (1999) Cementation of soils due to calcium carbonate. Soil Found 39:55-64. https://doi.org/10. 3208/sandf.39.6_55

Fukue M, Ono S-I, Sato Y (2011) Cementation of sands due to microbiologically-induced carbonate precipitation. Soil Found 51:83-93. https://doi.org/10.3208/sandf.51.83

Gao Y, Zhang J, Luosun Y (2014) Shrinkage stress in concrete under dry-wet cycles: an example with concrete column. Mech Time-Dependent Mater 18:229-252. https://doi.org/10.1007/ s11043-013-9225-1

Gowthaman S, Iki T, Nakashima K et al (2019a) Feasibility study for slope soil stabilization by microbial induced carbonate precipitation (MICP) using indigenous bacteria isolated from cold subarctic region. SN Appl Sci 1:1480. https://doi.org/10.1007/ s42452-019-1508-y

Gowthaman S, Mitsuyama S, Nakashima K et al (2019b) Biogeotechnical approach for slope soil stabilization using locally isolated bacteria and inexpensive low-grade chemicals: a feasibility study on hokkaido expressway soil, Japan. Soil Found 59:484-499. https://doi.org/10.1016/j.sandf.2018.12.010

Gowthaman S, Nakashima K, Kawasaki S (2020) Freeze-thaw durability and shear responses of cemented slope soil treated by microbial induced carbonate precipitation. Soil Found 60:840855. https://doi.org/10.1016/j.sandf.2020.05.012

Imran M, Kimura S, Nakashima K et al (2019) Feasibility study of native ureolytic bacteria for biocementation towards coastal erosion protection by MICP method. Appl Sci 9:4462. https:// doi.org/10.3390/app9204462

JGS (2012) Japanese standards and explanations of geotechnical and geoenvironmental investigation methods (3431-2012). Japanese Geotechnical Society, Tokyo, pp 426-432

Jiang N-J, Tang C-S, Yin L-Y et al (2019) Applicability of microbial calcification method for sandy-slope surface erosion control. J Mater Civ Eng 31:04019250. https://doi.org/10.1061/(ASCE) MT.1943-5533.0002897

Kalantary F, Kahani M (2019) Optimization of the biological soil improvement procedure. Int J Environ Sci Technol 16:42314240. https://doi.org/10.1007/s13762-018-1821-9

Khanlari G, Abdilor Y (2015) Influence of wet-dry, freeze-thaw, and heat-cool cycles on the physical and mechanical properties of upper red sandstones in central Iran. Bull Eng Geol Environ 74:1287-1300. https://doi.org/10.1007/s10064-014-0691-8

Li Y, Shi T, Li Y et al (2019) Damage of magnesium potassium phosphate cement under dry and wet cycles and sulfate attack. Constr Build Mater 210:111-117. https://doi.org/10.1016/j. conbuildmat.2019.03.213
Liu K-W, Jiang N-J, Qin J-D et al (2020) An experimental study of mitigating coastal sand dune erosion by microbial- and enzymatic-induced carbonate precipitation. Acta Geotech. https:// doi.org/10.1007/s11440-020-01046-z

Maleki M, Ebrahimi S, Asadzadeh F, Emami Tabrizi M (2016) Performance of microbial-induced carbonate precipitation on wind erosion control of sandy soil. Int J Environ Sci Technol 13:937-944. https://doi.org/10.1007/s13762-015-0921-z

Martinez BC, DeJong JT, Ginn TR et al (2013) Experimental optimization of microbial-induced carbonate precipitation for soil improvement. J Geotech Geoenvironmental Eng 139:587-598. https://doi.org/10.1061/(ASCE)GT.1943-5606.0000787

Meyer FD, Bang S, Min S et al (2011) Microbiologically-induced soil stabilization: application of Sporosarcina pasteurii for fugitive dust control. Geo-Frontiers 2011. American Society of Civil Engineers, Reston, VA, pp 4002-4011

Montoya BM, DeJong JT, Boulanger RW (2013) Dynamic response of liquefiable sand improved by microbial-induced calcite precipitation. Geotech 63:302-312. https://doi.org/10.1680/geot.SIP13.P.019

Moosazadeh R, Tabandeh F, Kalantary F et al (2019) Mitigation of the liquefaction potential of soil by ca-carbonate precipitation induced by indigenous urease-producing Staphylococcus sp. IR-103. Int J Environ Sci Technol 16:3657-3666. https://doi.org/10.1007/ s13762-018-1788-6

Nayanthara PGN, Dassanayake ABN, Nakashima K, Kawasaki S (2019) Microbial induced carbonate precipitation using a native inland bacterium for beach sand stabilization in nearshore areas. Appl Sci 9:3201. https://doi.org/10.3390/app9153201

Omoregie AI, Palombo EA, Ong DEL, Nissom PM (2019) Biocementation of sand by Sporosarcina pasteurii strain and technicalgrade cementation reagents through surface percolation treatment method. Constr Build Mater 228:116828. https://doi.org/ 10.1016/j.conbuildmat.2019.116828

Omoregie AI, Palombo EA, Nissom PM (2020) Bioprecipitation of calcium carbonate mediated by ureolysis: a review. Environ Eng Res. https://doi.org/10.4491/eer.2020.379

Salifu E, MacLachlan E, Iyer KR et al (2016) Application of microbially induced calcite precipitation in erosion mitigation and stabilisation of sandy soil foreshore slopes: a preliminary investigation. Eng Geol 201:96-105. https://doi.org/10.1016/j.enggeo.2015.12.027

Sun X, Miao L, Chen R (2020) The application of bio-cementation for improvement in collapsibility of loess. Int J Environ Sci Technol. https://doi.org/10.1007/s13762-020-02974-9

Tang CS, Cui YJ, Shi B et al (2011) Desiccation and cracking behaviour of clay layer from slurry state under wetting-drying cycles. Geod 166:111-118. https://doi.org/10.1016/j.geoderma.2011.07.018

Tang CS, Wang DY, Shi B, Li J (2016) Effect of wetting-drying cycles on profile mechanical behavior of soils with different initial conditions. CATENA 139:105-116. https://doi.org/10.1016/j.catena. 2015.12.015

Tang W, Mohseni E, Wang Z (2018) Development of vegetation concrete technology for slope protection and greening. Constr Build Mater 179:605-613. https://doi.org/10.1016/j.conbuildmat.2018.05.207

Tolba E, Müller WEG, Abd El-Hady BM et al (2016) High biocompatibility and improved osteogenic potential of amorphous calcium carbonate/vaterite. J Mater Chem B 4:376-386. https://doi.org/ 10.1039/C5TB02228B

van Paassen LA, Ghose R, van der Linden TJM et al (2010) Quantifying biomediated ground improvement by ureolysis: large-scale biogrout experiment. J Geotech Geoenvironmental Eng 136:17211728. https://doi.org/10.1061/(ASCE)GT.1943-5606.0000382

Wang X, Tao J, Bao R et al (2018) Surficial soil stabilization against water-induced erosion using polymer-modified microbially induced carbonate precipitation. J Mater Civ Eng 30:04018267. https://doi.org/10.1061/(ASCE)MT.1943-5533.0002490 
Wang Y, Soga K, Dejong JT, Kabla AJ (2019) Microscale visualization of microbial-induced calcium carbonate precipitation processes. J Geotech Geoenvironmental Eng 145:1-13. https://doi.org/10. 1061/(ASCE)GT.1943-5606.0002079

Whiffin VS, van Paassen LA, Harkes MP (2007) Microbial carbonate precipitation as a soil improvement technique. Geomicrobiol J 24:417-423. https://doi.org/10.1080/01490450701436505

Wu C, Chu J, Cheng L, Wu S (2019) Biogrouting of aggregates using premixed injection method with or without $\mathrm{pH}$ adjustment. J Mater Civ Eng 31:1-6. https://doi.org/10.1061/(ASCE)MT.19435533.0002874

Zhang J, Gao Y, Han Y, Sun W (2012) Shrinkage and interior humidity of concrete under dry-wet cycles. Dry Technol 30:583-596. https://doi.org/10.1080/07373937.2011.653614

Zhang ZB, Peng X, Wang LL et al (2013) Temporal changes in shrinkage behavior of two paddy soils under alternative flooding and drying cycles and its consequence on percolation. Geod 192:1220. https://doi.org/10.1016/j.geoderma.2012.08.009

Zhang C, Li F, Lv J (2017) Morphology and formation mechanism in precipitation of calcite induced by Curvibacter lanceolatus strain HJ-1. J Cryst Growth 478:96-101. https://doi.org/10.1016/j.jcrys gro.2017.08.019

Zhang X, Hu M, Guo X et al (2018) Effects of topographic factors on runoff and soil loss in Southwest China. CATENA 160:394-402. https://doi.org/10.1016/j.catena.2017.10.013

Zhao Z, Yang J, Zhang D, Peng H (2017) Effects of wetting and cyclic wetting-drying on tensile strength of sandstone with a low clay mineral content. Rock Mech Rock Eng 50:485-491. https://doi. org/10.1007/s00603-016-1087-9 